\title{
Os dois futuros do ato de governar: processos de descentralização e recentralização no ato de governar
}

B. Guy Peters

\section{Introdução}

O setor público, na maioria dos países, passou por mudanças significativas durante as últimas décadas. Quer as mudanças tenham sido descritas como “reforma”, "modernização", "reinvenção", ou qualquer outra denominação, a maior parte dos governos está agora bem diferente do que era há alguns anos. Essas transformações, em geral, produziram governos que são mais eficientes e eficazes. Além disso, embora a maioria das reformas implementadas tenha sido concebida dentro do modelo de mercado (Peters, 2001), a administração pública está atualmente, em muitos países, mais aberta à participação do público bem como mais receptiva ao envolvimento de escalões menores do funcionalismo público.

O modelo dominante de reforma do setor público nas últimas décadas tem sido discutido como o New Public Management (Hood, 1991; Christensen and Laegreid, 2001), ou simplesmente NPM. A idéia básica do NPM é a de que se deve tornar o governo mais eficiente e efetivo. Para alcançar esse propósito, é 
necessário que o setor público atue de modo similar ao setor privado. Um dos componentes dessas reformas tem sido ampliar a autonomia dos administradores e de suas organizações, partindo da premissa de que se o talento gerencial não estivesse confinado a normas internas, o setor público seria mais eficiente (Dilulio, 1994). Além disso, essa autonomia deveria ter sido ampliada pela criação de diversas organizações autônomas (ver NiSKANEN, 1971), como as Next Steps Agencies (Agências dos Próximos Passos) no Reino Unido.

Embora a dimensão participativa da mudança tenha sido discutida sotto voce em diversos processos de reforma, ela temse tornado um conceito mais central. Enquanto muitos dos estágios iniciais das reformas eram debatidos como o New Public Management ${ }^{1}$, o interesse crescente em reforma do tipo governança ampliava a dimensão participativa da mudança (Peters, 2005). Como a idéia da governança do New Public Management pode ser extremamente vaga como conceito (veja Pierre e Peters, 2000), ela tem sido objeto de significativas contestações acadêmicas. Isto posto, muitas das reformas do tipo governança implementadas por governos enfatizaram o papel de atores sociais em elaborar e implementar políticas e, principalmente, destacaram o papel das redes e estruturas análogas nos processos de governo de sociedades.

Apesar de o New Public Management e a reforma do tipo governança terem dado contribuições significativas à atuação do serviço público, também provocaram vários problemas no governo. Particularmente, ambos os estilos de reforma criaram problemas de incoerência e enfraquecimento da coordenação no setor público (ver Bakvis e Juillet, 2004) e, além disso, criaram extensos problemas de accountability (Mulgan, 2000). Portanto, como quase qualquer outra iniciativa de reforma anterior, tanto a NPM quanto as reformas do estilo governança engendraram outras novas ações, e o processo de tentar fazer com que o "governo trabalhe melhor e custe menos" segue incólume ${ }^{2}$. Semelhante ao que Herbert Simon argumentou notoriamente há 60 anos, muitos dos princípios usados na administração pública (e talvez na administração privada) têm opostos que, em circunstâncias adequadas, são igualmente válidos.

Dada a discussão acima, estamos lidando com algumas alternativas de futuro para o setor público na maioria das democracias industrializadas. Ambas envolverão mudanças, e ambas exigirão investimentos contínuos do capital político para alcançarem efetividade. Além disso, o aspecto central desses dois futuros é que não é preciso fazer uma escolha definitiva entre eles. Ambos são possíveis, e seus efeitos serão complementares. A questão política central não é fazer uma escolha entre os dois, mas sim achar uma forma de fazer com que ambos se complementem de maneira efetiva e democrática.

\section{Um futuro - continuação dos modelos atuais de reforma}

Embora eu venha discutindo as opções como modelos alternativos para o setor público, como de fato o são, os padrões de reforma que moldam o governo contemporâneo têm diversas coisas em comum. Dito de forma mais geral, essas reformas tendem a tirar do centro do governo o processo de governar e envolvem diversas mudanças nos padrões do ato de governar, incluindo: 
1) Desconcentração: Uma das mudanças mais importantes associadas ao New Public Management tem criado diversas organizações autônomas ou quase autônomas, geralmente chamadas de agências (Pollitt e Talbot, 2004; Verhoest, Rubecksen e Humphreys, 2007). Uma boa parte da elaboração e implementação das políticas nos sistemas políticos contemporâneos tem sido delegada a essas organizações, sob a premissa de que agências com um único objetivo e com autonomia administrativa permitirão que administradores públicos talentosos melhorem a qualidade dos serviços públicos. Essa desconcentração também representa certo menosprezo à política e aos políticos no processo de governança.

2) Descentralização: Assim como transferir algumas funções do setor público a organizações no governo central, outra estratégia tem sido descentralizar atividades e dar maior responsabilidade a governos subnacionais. A lógica da descentralização é, em parte, a de melhorar a eficiência, considerando-se que unidades menores prestarão melhores serviços. Além disso, a descentralização pode ser justificada em bases democráticas, com o povo dispondo, talvez, de maior oportunidade de envolvimento nos menores níveis da administração.

3) Delegação: Uma outra estratégia para reformar o Estado tem sido delegar autoridade pública a vários outros agentes (para modelos gerais veja Huber e Shipan, 2002). Utilizando o enfoque de mercado para governar, muito tem sido delegado a terceirizados e a outros atores do mercado. No modelo de governança, muitas responsabilidades seriam repassadas a redes e organizações sem fins lucrativos. Ambos os tipos de delegação podem ser pensados de forma a melhorar a eficiência do setor público, e o uso de redes de atores sociais também é considerado importante para otimizar o elemento democrático do ato de governar.

Poderíamos adicionar elementos a essa lista de descrições de mudança, mas todas as reformas mencionadas neste artigo envolvem a descentralização do processo de governar (veja também Peters, 2004). Embora, obviamente, diferente nos termos de seus detalhes e justificações, o impacto de todas as mudanças no setor público tem minimizado o controle do governo central, incluindo presidentes, primeiros-ministros e até ministros. ${ }^{3}$ Assim, todas partem da premissa - explícita ou implícita - de que o governo trabalhará melhor se o centro político for desvalorizado e se os administradores públicos e os agentes do setor privado forem mais responsáveis na prestação de serviços.

\section{Da reforma aos novos problemas criados pela reforma}

As mudanças no público anteriormente mencionadas são geralmente justificadas pela lógica familiar de "direcionar e não fazer" (Osborne e GAEBler, 1991), presumindo que os governos são melhores em estabelecer direções para as políticas do que na produção de resultados. $\mathrm{Na}$ verdade, entretanto, essas reformas também podem ter reduzido a capacidade de direção do setor público e, especialmente, diminuído a capacidade que as autoridades políticas gozavam no passado de exercer controle sobre as políticas de seus governos. A redução do primado da política ${ }^{4}$ tem, por sua vez, criado alguns problemas de governança:

\section{1) Políticos e direção}

Como já sugerido, a ênfase em deslocar atividades para longe do centro 
do governo reduziu a capacidade de autoridades eleitas exercerem controle sobre essas políticas, ainda que, nas políticas democráticas, presuma-se que as eleições sejam para eleger políticas (veja Rose, 1974; Caplan, 2007). São tantas as atividades políticas delegadas que os líderes dispõem de poucas alavancas - em geral, de baixa qualidade, com as quais possam afetar o curso de seus próprios governos. Alguns primeiros-ministros expressaram seus sentimentos de impotência no contexto dos modelos contemporâneos de governo, mas poucos realmente fizeram algo para tentar recompor o equilibrio.

\section{2) Coordenação}

Uma segunda dificuldade resultante da descentralização do setor público tem sido a de reduzir os níveis de coordenação entre políticas públicas e organizações. A noção de dividir grandes organizações em várias menores, conferindo a estas maior autonomia, tem sido central para as reformas, especialmente na criação de agências. As diversas organizações que trabalham com maior autonomia tendem a exacerbar os problemas familiares de coordenação e coerência no setor público. A proliferação de organizações, por sua vez, também contribui para as dificuldades no exercício do controle político.

\section{3) Complexidade}

O maior número de organizações envolvidas no ato de governar e a diversidade de maneiras pelas quais estão legalmente ligadas às partes mais convencionais do setor público também aumentam a complexidade do ato de governar. Embora a complexidade não seja prejudicial em si, ela pode contrariar alguns dos ganhos de eficiência gerados pelas mudanças na administração. Isto é, o número crescente de pontos com direito a veto no sistema e a dificuldade de ganhar aceitação de todos esses pontos reduz as chances de sucesso. Além disso, a complexidade tende a reduzir a transparência do sistema público e, portanto, afeta a responsabilidade.

\section{4) Captura}

Ao separar as organizações públicas das conexões diretas com as autoridades políticas, as reformas de descentralização tendem a tornar tais organizações mais vulneráveis a serem capturadas por outros interesses. Esse é um problema clássico na análise de agências reguladoras independentes, tanto nos Estados Unidos quanto em outros países, mas a lógica pode ser estendida de forma a cobrir uma gama de outras organizações que foram desligadas do apoio político. A captura pode ser por interesses geográficos (Whitford, 2002) ou por interesses funcionais, mas a idéia do governo despolitizado tende a levar a outras formas de politização, geralmente de tipo menos desejável.

\section{5) Accountability}

Finalmente - e talvez o mais importante - as reformas no setor público criaram maiores problemas de accountability. Uma virtude do primado da política é que ela identifica claramente a hierarquia da responsabilização no setor público, apontando ainda diversos mecanismos para fazer valer tal responsabilização. Quando há uma série de relações alternativas entre os políticos eleitos e a prestação de serviços, e inúmeros prestadores de serviço agindo de forma autônoma, torna-se difícil identificar a responsabilidade pelas ações.

Portanto, tanto da perspectiva da teoria democrática quanto da perspectiva da capacidade das políticas, as reformas 
associadas ao enfoque da New Public Management, assim como as que vêm da abordagem da governança, geraram uma necessidade substancial de mudanças adicionais. Como destacarei abaixo, tais mudanças não podem ser um simples retorno ao status quo anterior com domínio do setor público, embora alguns acadêmicos sugiram um retorno às formas mais tradicionais de administração pública (OlsEn, a ser lançado). Muitas mudanças ocorreram e os governos aprenderam muito sobre mecanismos alternativos de prestação de serviços para que seja feito um simples retorno ao modelo de governo burocrático e hierárquico (veja WaLSH e STEWART, 1992). Em parte, tais mudanças no setor público, associadas a esses dois movimentos de reforma, criaram uma melhora substancial no funcionamento do setor público, pelo menos nos níveis mais micro. ${ }^{5}$

No entanto, o afastamento desse estilo de governo tem sido de certa forma exagerado, e muitas coisas do sistema antigo permaneceram em funcionamento se vistas sob a fachada das novas formas de governar (Schofield, 2001). Além disso, alguns acadêmicos discutem o retorno ao estilo weberiano de governar, em muitos aspectos, como uma necessidade percebida de revigorar alguns dos mecanismos de controle e probidade que eram componentes das formas de governar mais tradicionais. Isso está longe de ser apenas reacionário, mas representa a necessidade de recriar alguns valores que eram centrais na concepção de governos tanto efetivos quanto responsáveis, e que não foram adequadamente substituídos pelos produtos da reforma.

Deixando de lado o retorno a um estilo mais weberiano de governo, muitos dos problemas gerados pelo NPM e pelas reformas do tipo governança podem ser condensados no problema do governo democrático. Novamente, se as eleições tratam de escolher tanto políticas quanto líderes, e se tais líderes, uma vez eleitos, acharem que exercem menos influência nas políticas do que eles mesmos acreditavam - e, provavelmente, seus eleitores consideram apropriado então há um problema fundamental de democracia. Mesmo que os líderes eleitos

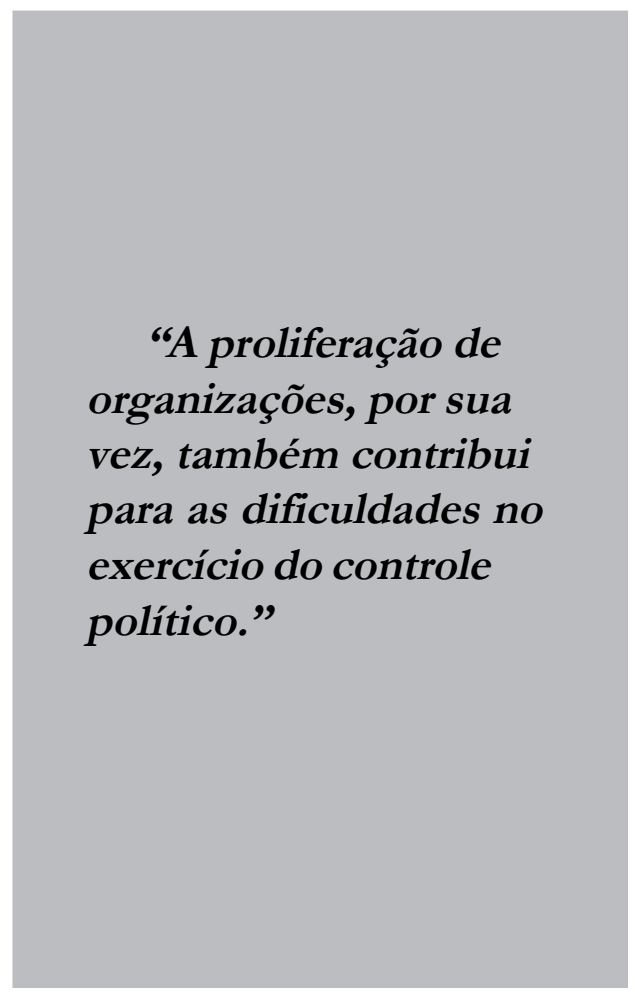

sejam capazes de seguir no fluxo da atual corrente, seu nível de controle das políticas pode não ser tão grande como desejado. Essa perda de controle sobre as políticas é uma evidência ao se fazer escolhas de políticas, mas fica ainda mais aparente dado o papel crucial que a implementação desempenha na determinação do verdadeiro significado das políticas (Meyers e Vorsanger, 2004). 


\section{O centro contra-ataca}

Tendo reconhecido suas próprias dificuldades em exercer controle sobre o setor público, diversos governos começaram a tomar medidas para tentar recompor esse controle. Em algumas instâncias, essa mudança de rumo sobre o ato de governar refletiu em circunstâncias políticas especiais, incluindo mudanças nos partidos políticos que controlam o setor público. Em outros casos, a tentativa de impor novamente um maior controle político refletiu em mais mudanças fundamentais no ideário do ato de governar. Tais mudanças, reagindo a esses problemas criados pelo New Public Management e a outros problemas, não tiveram a generalização do NPM ou das reformas de governança, mas refletem, de fato, a necessidade de retomar algumas das direções políticas que foram perdidas.

Algumas tentativas de impor de novo esse controle sobre o ato de governar tenderam a ir contra vários dos cânones da "boa governança". Quando confrontados com a quantidade de organizações e programas sobre os quais percebem que exercem menos controle direto, os líderes políticos tendem a politizar a gestão desses programas. Diversos estudos sobre o setor público em democracias industrializadas (Peters e Pierre, 2004) mostraram que líderes políticos se encontraram na posição de ter que assumir responsabilidade política por programas sobre os quais têm pouca capacidade de influenciar diretamente, e essa é uma posição extremamente desconfortável para esses líderes. Um dos meios mais simples de tentar ganhar o controle é ter pessoal próprio administrando esses programas, mudá-los, por exemplo, para níveis maiores de designação política. De forma paradoxal, a desre- gulamentação interna do trabalho público promovida pelo NPM facilitou tais designações. ${ }^{6}$

Além da politização, a descentralização do Estado tende a engendrar a identificação de "bodes expiatórios" e da negação da responsabilidade. Como mencionado, os líderes políticos podem acreditar que estão sendo responsabilizados sem justificativa, e, por sua vez, tentam se livrar de tal responsabilidade. Até certo ponto essa reclamação tem fundamento, visto que várias das conexões associadas à responsabilidade efetiva e ao dever de prestar contas - accountability - foram enfraquecidas e muitos dos mecanismos de controle foram eliminados. $\mathrm{Na}$ verdade, alguns dos mecanismos aparentemente usados em uma tentativa de criar responsabilidade pela prestação de serviço podem, no final, diluir essa responsabilidade. Por exemplo, o uso crescente de czarismo ${ }^{7}$ em áreas problemáticas do serviço público tende a desviar a atenção, e potencialmente a accountability dos líderes políticos e se voltar para a direção do "czar"

Nem todas as reações à perda de controle político foram tão negativas quanto as já discutidas. Talvez o mais óbvio seja que alguns governos vêm tentando construir mecanismos de coordenação para alguns programas e organizações autônomas que foram criados. Uma das tentativas mais óbvias é o movimento "joined up governement" (governo agrupado) no Reino Unido, mas houve programas análogos em diversos outros países (Pollitt, 2005; Christensen e Laegreid, 2007; Gregory, 2004). A idéia básica tem sido a tentativa de integrar o governo depois de ele ter sido desagregado por regimes anteriores. Em alguns casos, a tentativa foi estrutural, mas em outros houve uma pressão mais intelectual de 
tentar criar um governo mais "holístico", que pudesse fornecer uma rede de serviços relativamente integrada (6, LEAT, SETZLER e STOKER, 2004).

De certa forma, a noção de adesão ao governo - uma contribuição válida ao ato de governar - carece de alguns elementos cruciais das reformas descentralizadoras. As tentativas de melhorar a coordenação foram realmente agrupando os governos e aparentemente estavam menos interessadas em aglutinar os outros aspectos não governamentais do ato de governar, também importantes. Sinceramente, a tentativa de produzir integração nesse nível seria mais difícil, e talvez até contraproducente, caso avaliada por perspectivas mais convencionais do ato de governar. Em suma, tentar colocar as várias relações com os agentes sociais em um único formato, e/ou reduzir a autonomia, pode eliminar os ganhos obtidos com as reformas anteriores sem necessariamente criar benefícios proporcionais.

\section{O hiato}

Essa discussão revela a presença de dois formatos distintos de governança contemporânea. Como já observado, esses dois estilos, embora distintos, são também, em grande medida, complementares. Um estilo de governança enfatiza a necessidade de melhorar a qualidade da prestação de serviços, a administração das organizações individuais e a democratização desses serviços. As reformas associadas tanto ao NPM quanto à governança têm sido bem sucedidas em diversos casos, mas criaram a necessidade de um segundo padrão de mudanças, enfatizando a necessidade de coordenar, criar uma maior coerência e restaurar a prioridade da política. Cada um desses enfoques no ato de governar constitui uma contribuição importante à capacidade de fornecer uma gestão melhor, embora muito diferentes. A maior tarefa no ato de governar pode ser, portanto, a de "costurar" as duas alternativas.

Além dos assuntos práticos envolvidos no ato de governar, essas duas abordagens representam preocupações teóricas interessantes. Por um lado, houve desenvolvimentos teóricos importantes na área de governança (Sørenson and Torfing, 2000; Kuijn and Koopenjan, 2005). Esse termo assume diferentes significados, mas talvez a linha dominante enfatize a necessidade de se considerar o processo de fornecer direções à sociedade, bem como o de assegurar serviços públicos, envolvendo atores além dos nominalmente no setor público. Portanto, as reformas de governança abrangem o envolvimento de uma grande variedade de atores para fazer e prestar serviços, sendo que tal envolvimento é mostrado e justificado em um crescente corpo da literatura científica social.

Pode-se argumentar que a preocupação com a governança seja algo velho em nova roupagem, pois, especialmente nos países do norte da Europa, existe uma variedade de corporativismo e pluralismo corporativo (RokKAN, 1967) há décadas, se não há séculos. A realidade do envolvimento de agentes sociais com o setor público mudou, de certa forma, com o fortalecimento das redes. Além disso, a teoria que cerca tal envolvimento dos agentes do setor privado certamente mudou. Por exemplo, em vez de grande parte do envolvimento ser motivada pelo próprio Estado (mesmo que no modelo pluralista corporativo), modos contemporâneos de governança permitem que uma maior autonomia seja exercida por agentes sociais e por mais organizações autônomas de redes que existem para fornecer a governança ${ }^{8}$. 
Embora a teoria de governança, bem como o seu desenvolvimento da lógica de redes tenha dado diversas contribuições para o entendimento dos processos de mudança na economia e na sociedade, também causou vários problemas internos. Vale destacar a suposição da capacidade das redes para tomar decisões. O modelo de redes parece servir para as condições nas quais os atores principais concordam nos objetivos e formas, mas, paradoxalmente, se existisse tal nível de acordo, então não haveria a necessidade de redes ${ }^{9}$. Embora as redes sejam apresentadas como alternativas às formas convencionais de governo, elas são carentes de normas de decisão predeterminadas que permitam a tomada de decisões nas circunstâncias mais difíceis e também legitimem tais decisões ${ }^{10}$.

Além dos problemas na tomada de decisões, a ausência de normas claras de decisão pode fazer com que as decisões fiquem aquém das expectativas. Conforme Fritz Scharpf (1988) argumenta, a necessidade de se alcançar consenso pode levar a decisões pelo denominador comum mais baixo. Se há múltiplos distritos eleitorais com idéias potencialmente diferentes sobre políticas públicas, a forma de resolução dos conflitos pode estar nos poucos pontos de concordância. Os resultados mais ou menos incrementais desse tipo de processo de tomada de decisões podem agradar interesses estabelecidos nas redes de trabalho, mas pouco agregam à capacidade de inovação e a uma mudança maior das políticas públicas (ver Dente, Bobbio e Spada, 2003). A implementação seria, então, facilitada porque a oposição potencial para a mudança estaria cooptada a essa decisão.

Finalmente, e talvez o mais importante, a delegação de quantidade substancial de poder levou a problemas centrais da democracia. Tais questões democráticas envolvem não só a responsabilidade, mas também a representatividade - ambos valores democráticos fundamentais. Isso é, com certeza, bastante parodoxal, já que uma das principais justificativas para, pelo menos, alguns dos aspectos da delegação de autoridade, é a de ampliar o envolvimento do público. Apesar das boas intenções, apenas os membros de certos grupos estariam envolvidos nas redes de trabalho e, especialmente, os "grupos potenciais", que apresentam baixos níveis de organização, não estariam adequadamente representados.

Esses desafios para a teoria da governança refletem de perto os problemas enfrentados por governos no "mundo real". A delegação para redes de trabalho, contratados, governos locais ou quaisquer outros atores que possam ser usados para fazer e implementar políticas públicas cria problemas institucionais, não possibilitando aos líderes políticos o exercício de um controle efetivo (Huber e SHIPAN, 2002). Quer o problema seja abordado em termos de líderes e agentes, quer em termos de questões de controle mais abertamente político, os críticos da governança têm questionado a capacidade desses modelos para explicar adequadamente a seleção e a prestação real de serviços, especialmente em uma estrutura democrática.

\section{Superação do hiato: metagovernança}

O desenvolvimento teórico da governança agora se estende à idéia de metagovernança, significando, na essência, a governança da governança (ver O’TOOLE, 2007). A fraqueza da governança, como um conceito abrangente para descrever o que 
ocorre nos processos contemporâneos de governança, tornou-se mais transparente, até para alguns dos defensores desse enfoque. Essa consciência criou a necessidade de se pensar sobre os significados de construir, nos processos governamentais, maior controle, permitindo, ainda, certa autonomia para as redes e outras formas de governo descentralizado. Qualquer conceituação razoável de processos atuais de governança deve conter uma grande parte de atividades descentralizadas, reconhecendo a impossibilidade de se voltar ao status quo anterior. No entanto, essa conceituação também deve reconhecer que todas as funções requeridas para governar uma sociedade não podem ser preenchidas por aqueles processos descentralizados ${ }^{11}$.

O desenvolvimento de um conceito de trabalho de metagovernança ajuda, portanto, a superar a lacuna entre os processos desagregados no setor público contemporâneo e o desejo de muitos líderes políticos de restaurar algum controle direto. Em termos mais reducionistas, a metagovernança seria simplesmente renunciar às delegações de poder e recentralizar os controles nas estruturas associadas ao setor público convencional. Uma resposta assim simplista tem pouca probabilidade de alcançar sucesso, não sendo, assim, politicamente viável. ${ }^{12}$ As reformas das últimas décadas não são impopulares com tantas pessoas dentro e fora do governo e criaram suas próprias bases de apoio. Além disso, a ideologia da New Public Management continua a ser vastamente aceita e essas idéias vêm motivando escolhas de políticas públicas relacionadas à administração interna. O discurso que cerca a administração pública foi alterado de uma maneira fundamental. Dessa forma, qualquer resposta simplista e atávica tem pouca probabilidade de ser aceita.
Assim como pensar em metagovernança como uma reação simples às mudanças no setor público, e uma tentativa de recriar o passado, esse conceito também deve ser entendido como propiciador de condições que assegurem modelos de governança passíveis de desempenho mais efetivo. Por exemplo, boa parte da literatura sobre governança assume que redes de trabalho se autoorganizam e são autônomas, mas em

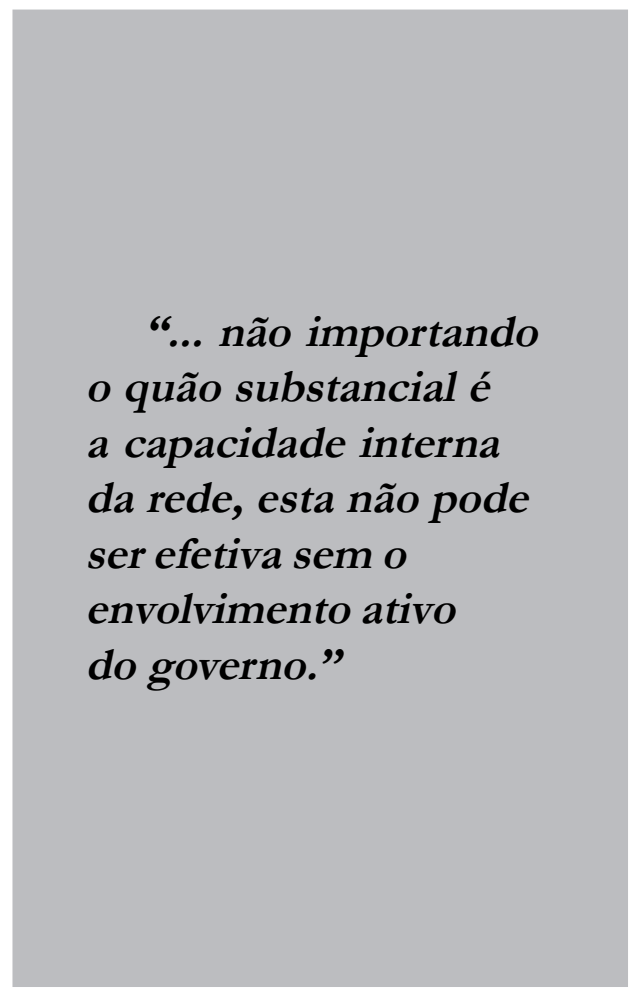

muitos casos estas devem ser criadas e providas pelo Estado. Da mesma maneira, para ser efetiva, uma rede deve ter um ponto de acesso no setor público que legitime e motive o envolvimento de seus integrantes, com as burocracias públicas fornecendo a maior parte dos pontos de acesso. Além disso, as ações de qualquer rede de políticas teriam de ser legitimadas e as próprias instituições formais do setor 
público podem ser cruciais para essa legitimação. Em resumo, não importando o quão substancial é a capacidade interna da rede, esta não pode ser efetiva sem o envolvimento ativo do governo.

\section{Os instrumentos da metagovernança}

Os governos têm à sua disposição as mesmas ferramentas da metagovernança que dispõem para lidar com outros problemas de políticas públicas. Mas esses mecanismos estão disponíveis em combinações um tanto diferentes. Em parte, isso se deve às tarefas específicas associadas à metagovernança em oposição à tentativa de influenciar a sociedade. A metagovernança envolve o exercício de moldar os comportamentos das organizações que possuem legitimidade política própria, não viabilizando assim parte do relacionamento ou autoritário usual. A conjugação de ferramentas para metagovernança também é diferente hoje, pois houve certo movimento na direção da "Nova Governança" (Salamon, 2001), implicando o uso da negociação, barganha e espectros mais amplos de conformidade do que nos estilos de comando e controle. Considerando-se as diferenças gerais entre metagovernança e governança, é necessário apontar alternativas ou complementos aos mecanismos convencionais.

\section{Definindo prioridades}

Talvez a estratégia fundamental da metagovernança seja o estabelecimento de prioridades, determinando-as politicamente. Uma fraqueza fundamental nas redes e em outras formas de governo descentralizadas é a de que todos os programas e objetivos são virtualmente iguais. Essa igualdade é, em grande parte, uma função de autoridade delegada às organizações, sendo que todas presumem que seus programas são tão valiosos quanto os programas das outras. Da mesma maneira, mesmo que os aspectos descentralizados de governo sejam as organizações autônomas e quase autônomas, ainda assim estas assumirão que recebem essa autonomia para buscar seus próprios objetivos, em vez de qualquer um mais abrangente para o "governo como um todo". ${ }^{13}$

O estabelecimento de prioridades pode ser realizado de diversas formas. A maioria envolve a melhoria da capacidade de presidentes, primeiros-ministros e suas agências centrais. Essa necessidade de fortalecer o centro pode parecer irônica, devido à tendência dos regimes parlamentares em discutir a "presidencialização" da política, mas o foco no chefe executivo é, em geral, mais um evento da mídia do que uma reflexão da capacidade de governança (Peters, 2007). Há, porém, tentativas reais para fortalecer o centro e estabelecer prioridades. Por exemplo, na Finlândia foram criados programas transversais como componentes dos documentos de coalizão para cada novo governo (Bouckaert, Ormond and Peters, 2000). Outros governos tentaram restaurar a capacidade de governar pelo centro (SAvoie, 2004), embora esta pareça mais fraca do que o esperado.

\section{Lei Branda}

Se os usos convencionais da autoridade não são apropriados para essas tarefas de metagovernança, então algumas alternativas mais brandas podem apresentar a resposta necessária. A mudança para essa lei branda foi evidente não só na metagovernança, como também tem sido aplicada a uma gama de situações em outros elementos da nova governança (Мотн, 
2003). A noção básica desse enfoque de governo é o uso de instrumentos tais como marcadores de nível, diretrizes, estruturas e diversas outras formas de mecanismos que estabelecem níveis de conformidades no lugar de pontos específicos de conformidade. Além disso, esses instrumentos tendem a ser os produtos de discussões e negociações, em vez de serem imposições de superiores

A natureza da lei branda é estabelecer níveis de conformidade, oferecendo uma direção em vez de comandar ações. Essa resposta ao problema da metagovernança reflete a necessidade de direcionar, embora a distância, permitindo, assim, diferentes respostas das redes ou de governos locais. A maleabilidade da lei pode variar dependendo do objeto em foco. Por exemplo, a tentativa de controlar governos subnacionais que têm alguma base política própria pode ser mais desafiador do que controlar membros privados de uma rede. Além disso, a capacidade de usar a lei branda efetivamente pode variar de acordo com as áreas de política, envolvendo mais diretamente os poderes formais do Estado do que os estilos informais de direção e de governança. ${ }^{14}$

\section{Seguir o melhor caminho}

As estratégias de descentralização do governo e abrandamento de controle envolvem a minimização dos controles diretos sobre organizações e redes. Para os atores do centro, entretanto, reduzir níveis de controle pode não significar abandoná-los completamente, pois algumas formas podem ser mantidas, permitindo autonomia em outras áreas de atividade. De fato, um dos aspectos mais interessantes das discussões contemporâneas acerca da autonomia e do controle do setor público é a "dança" conduzida por estruturas e agências de controle central, organismos e governos locais para os quais a autonomia substancial foi concedida, ao menos em teoria (ver Yesilkagit, 2007).

Analiticamente, já discutimos (Bouckaert, Peters and Verhoest, 2007) em outros textos a autonomia de organizações públicas que abrangem três dimensões consideráveis - financeira, recursos humanos e políticas públicas. Portanto, uma organização pode dispor da liberdade de tomar suas próprias decisões sobre política de pessoal e gastos, mas o centro pode reter o controle sobre essas escolhas. A evidência disponível, mesmo não expressa em termos de metagovernança, recai sobre o fato de que os governos centrais tendem a manter o controle financeiro, usando-o para assegurar uma conformidade adequada às outras dimensões de atividade (WANNA, Jensen and De Vries, 2004). A manutenção dos controles pelo centro pode ser estratégica ou operacional. Ou seja, as organizações podem tanto tentar controlar a situação da ação das organizações autônomas quanto podem se valer de uma administração mais direta das decisões do dia-a-dia. A primeira opção se aproxima mais claramente da lógica de "mudar a direção a distância", mas ambas representam uma diminuição da autonomia real das organizações.

O ponto central dessa discussão é que autonomia e controle podem não ser tão incompatíveis na prática quanto conceitualmente aparentam. A lógica da metagovernança, e da "costura" a qual mencionei, é que ambos os conceitos devem coexistir, e assim prosseguir dentro dos sistemas políticos atuais. Conforme já argumentado sobre a utilização da lei branda como um instrumento para metagovernança, a atual 
conjugação de autonomia e controle se faz contingencial e duvidosa, a depender de sistemas políticos especiais. A tarefa tanto para o analista acadêmico quanto para o profissional militante é identificar as associações que podem, ao mesmo tempo, fornecer controle político efetivo (democrático) e manter os ganhos de eficiência que parecem ter resultado de muitas reformas do NPM. Enquadrar esse círculo mantendo um ou outro controle primário, geralmente o orçamento, pode ser uma estratégia efetiva para a metagovernança.

\section{Gestão de desempenho}

Finalmente, o uso crescente de gestão de desempenho em quase todas as democracias desenvolvidas, e em muitos outros sistemas, fornece um meio de controlar potencialmente as organizações autônomas (ver OECD, 2007; Peter, 2007). Embora o termo possa ser usado de diversas formas, a idéia fundamental é que, pelo uso de metas mensuráveis para os resultados dos programas públicos, as organizações centrais de controle podem monitorar e controlar o comportamento dessas organizações. Essa técnica muda, portanto, o mantra do New Public Management de "deixe os administradores administrarem" para "faça os administradores administrarem", significando que algumas das liberdades inerentes às idéias de administração do NPM foram perdidas em favor de mandatos para os administradores.

A gestão do desempenho tem alguns atributos em comum com a lei branda como instrumento para metagovernança. Em especial, esse método se apóia na negociação de estruturas e contratos para impor controle sobre a prestação de serviços das organizações, bem como sobre os indivíduos envolvidos nesses programas. As metas que são estabelecidas na gestão de desempenho tendem a ser flexíveis, ou progressivas, de forma a tornar o direcionamento mais "brando" e permitir que as organizações envolvidas disponham de certa liberdade na forma como alcançam as metas de desempenho. Além disso, os níveis de conformidade tendem a ser progressivos, garantindo que os níveis de desempenho de qualquer organização possam ser negociados ano após ano, a partir de uma habilidade continuada que afete os resultados da gestão de desempenho.

A gestão de desempenho pode ajudar a resolver diversos problemas criados por antigas reformas do setor público. Por exemplo, gestão e medidas de desempenho são usadas internamente entre os ministérios e seus componentes, incluindo contratantes e instituições formais do serviço público, configurando importantes elementos de monitoramento e mudanças de direção. No entanto, quando aplicada mais diretamente por organizações externas parlamentos, auditores, agências centrais a gestão de desempenho passa a ser um componente útil para a accountability. E, especialmente, quando os padrões de desempenho se tornam públicos, tais indicadores são especialmente importantes para alcançar essa responsabilidade, bem como para estabelecer um contexto democrático geral para ação.

\section{Conclusão}

A governança foi - e continua a ser uma mercadoria escassa em muitos países. De diversas formas, a capacidade de governar foi ampliada significativamente nas últimas décadas a partir da divulgação de idéias do New Public Management e das idéias de governança. Esses enfoques 
para governar tendem a ampliar a autonomia dos componentes mais baixos no sistema de governo, quer sejam governos locais, agências ou redes que interligam agentes públicos e privados. A capacidade das organizações em fazer suas próprias escolhas somada a de empregar técnicas de gestão não familiares ao setor público tende a tornar o governo mais eficiente e eficaz na prestação de serviços.

Apesar de os aspectos da reforma do setor público terem sido bem sucedidos, os problemas de responsabilidade e controle resultaram em uma subseqüente rodada de mudanças. Embora seja impossível retornar aos modelos de governança, antes objeto das reformas do NPM e da governança, são necessários alguns mecanismos para abordar a responsabilidade e outros temas democráticos fundamentais. As conseqüências negativas das reformas produziram algumas novas formas de governo, discutidas aqui como metagovernança.
A tarefa primária da governança, como destacado neste artigo, é a de costurar essas duas linhas de mudança no setor público. Enquanto um fio representa os caminhos eficientes do ato de governar, o outro ilustra melhor as aspirações políticas e, especialmente, democráticas. $\mathrm{O}$ ponto fundamental é que essas duas variáveis podem ser entrelaçadas efetivamente. Tal junção depende de vários fatores contingenciais. A primeira rodada de reformas - principalmente o NPM tendeu a assumir que uma medida cabe a todos, mas a habilidade para usar técnicas de gestão, bem como os tipos de metagovernança viáveis, depende de diversos fatores políticos e também de políticas públicas que suscitam explicações adicionais. Portanto, a tarefa de lidar com a governança continua a exigir pesquisas e análises amplas tanto pelos profissionais militantes quanto pelos analistas acadêmicos.

(Artigo recebido em janeiro de 2008. Versão final em outubro de 2008).

\section{Notas}

${ }^{1}$ Este termo foi, e é, extremamente amplo e de certa forma incluía idéias de participação bem como conceitos de eficiência com base no Mercado. Ver Hood (1991).

${ }^{2}$ Essa frase foi, obviamente, o subtítulo do Relatório de Desempenho Nacional (National Performance Review).

${ }^{3}$ Esse argumento parece estar em contradição direta com o que é geralmente encontrado na política comparativa, que enfatiza o declínio de governos parlamentares e mesmo de governos de gabinete em favor da dominação de primeiros ministros - geralmente chamado incorretamente de presidencialização de regimes parlamentares (veja Von Mettenheim, 1997; Heffernan, 2003). Tal argumento, entretanto, foca mais no controle político do processo no governo e mudanças no foco da mídia do que na real capacidade de executivos políticos de controlar as políticas.

${ }^{4}$ Esse termo é comumente utilizado. Para os primeiros usos, veja Pollock (1951).

${ }^{5}$ Quero dizer com isso que quanto mais se está próximo da provisão de serviços propriamente dita, e especialmente das operações de organizações individuais, maiores têm sido os benefícios da reforma. Quando fatores governamentais mais sistêmicos são considerados, os benefícios das reformas podem ser irrelevantes e os custos podem superar os benefícios. 
${ }^{6}$ É bem possível que tais indicações sejam perfeitamente qualificadas como administradores, mas está muito claro que há mais formas políticas de indicação, e que tais indicações dão a aparência de politização do setor público de uma forma que é inaceitável em muitos sistemas políticos.

${ }^{7}$ O governo do Tony Blair no Reino Unido foi o mais entusiasta no uso de czars para problemas como serviços ferroviários, diversos aspectos do Serviço Nacional de Saúde e uns voltados às crianças, entre outros. Esse mecanismo permite que o Primeiro Ministro ou um outro ministro argumente que algo foi feito e, por meio disso, tentar escapar da responsabilidade política pessoal.

${ }^{8}$ Alguns acadêmicos da governança notam a extensão da importância do Estado e o seu papel crucial para estabelecer o quadro onde os atores sociais envolvidos ganham poderes para fazer e implementar as políticas públicas. Da mesma forma, as redes poderiam ter pouca razão de existir se autoridades estatais, até mesmo delegadas, estivessem disponíveis para implementar as decisões tomadas. Esses fatores são cruciais para os argumentos de metagovernança apresentados abaixo.

${ }^{9} \mathrm{O}$ caso mais óbvio seria o das comunidades epistêmicas, onde há um acordo baseado em um corpo de conhecimento comum profissional ou científico (ver Adler, 1992).

${ }^{10}$ A regra da maioria, em legislaturas, por exemplo, permite que decisões sejam tomadas mesmo em face de um conflito, enquanto a lógica mais consensual de redes pode gerar alguma dificuldade na tomada de decisões. Além disso, como essas regras constitucionais de decisão são conhecidas antecipadamente, elas tendem a legitimar tais decisões, pelo menos no sentido processual do termo (Buchanan e Tullock, 1962).

${ }^{11} \mathrm{Sim}$, trata-se de um enfoque funcional para política e governos. Embora geralmente malvistos, os enfoques funcionais têm a capacidade de identificar temas importantes e também possíveis soluções para esses problemas. Em especial, saber o que deve ser feito para governar ajuda a entender por que os formatos descentralizados podem ser inadequados.

12 As políticas envolvidas aqui são mais provavelmente políticas institucionais, defendendo as prerrogativas de organização ou de programa ao invés de políticas partidárias. Esses interesses institucionais podem, evidentemente, estar ligados aos interesses sociais servidos pelas organizações envolvidas.

13 Esse termo foi usado pelo governo australiano e por várias outras nações para indicar a importância da criação de enfoques mais abrangentes ao ato de governar. Mesmo nesses casos, entretanto, as conexões de prestação de serviços com as organizações do setor privado, e mesmo com os governos subnacionais, ao disponibilizar serviços públicos são freqüentemente institucionalizadas de forma não adequada. (2004).

${ }^{14}$ Por exemplo, veja a discussão de mecanismos de governança informal por Helmke e Levitsky

\section{Referências}

6, P., D. Leat, K. Setzler e G. Stoker (2002): Toward Holistic Governance: The New Reform Agenda (Basingstoke: Palgrave).

Adler, E. (1992): The Emergence of Cooperation: National Epistemic Communities and the International Evolution of the Idea of Nuclear Arms Control, International Organization 46, 105-15. School of Governance). 
Bakvis, H. e L. Juillet (2004): The Horizontal Challenge: Line Departments, Central Agencies and Leadership (Ottawa: Canadá)

Bouckaert, G., D. Ormond e B. G. Peters (2000): A Possible Governance Agenda for Sweden (Helsinki: Ministério das Finanças).

Buchanan, J. M. e G. Tullock (1962): The Calculus of Consent (Ann Arbor: University of Michigan Press).

Caplan, B. (2007): The Myth of the Rational Voter: Why Democracies Choose Bad Policies (Princeton: Princeton University Press).

Christensen, T. e P. Laegreid (2001): New Public Management: Transformation of Ideas and Practice (Aldershot: Ashgate).

. (2007): Transcending New Public Management: The Transformation of

Public Sector Reforms (Aldershot: Ashgate).

Dente, B., L. Bobbio e A. Spada (2003): Government or Governance of Urban Innovation? DISP (Zurique) 162 (3), 1-22.

DiIulio, J. J. (1994): Deregulating Government (Washington, DC: The Brookings Institution).

Gregory, R. (2004): All the King's Horses and All the King's Men: Putting the New Zealand Public Sector Together Again, International Public Management Journal 4 (2), 41-58.

Heffernan, R. (2003): Prime Ministerial Predominance? Core Executive Politics in the United Kingdom, British Journal of Politics and International Relations 5, 347-72.

Helmke, G. e S. Levitsky (2004): Informal Institutions and Comparative Politics: A Research Agenda, Perspectives on Politics 2, 725-40.

Hood, C. (1991): A Public Management for All Seasons? Public Administration 69 (1), 3-19.

Huber, J. D. e C. R. Shipan (2002): Deliberate Discretion (Cambridge: Cambridge University Press).

JENSEN, L. (2004): Den store koordinator (Kobenhavn: Jurist og Økonomi)

KLIJN, E.-H. e J. KoOpenhaAn (2005): Managing Uncertainties in Networks (Londres: Routledge).

Marinetto, M. (2003): Governing Beyond the Centre: A Critique of the AngloGovernance School, Political Studies 51, 592-608.

Meyers, M. K. e S. Vorsanger (2004): Street-Level Bureaucrats and the Implementation of Public Policy, in B. G. Peters and J. Pierre, eds., The Handbook of Public Administration (Londres: Sage).

MorTH, U. (2003): Soft Law in Governance and Regulation: An Interdisciplinary Analysis (Cheltenham: Edward Elgar).

Mulgan, G. (2000): Accountability: An Ever-expanding Concept, Public Administration $78,555-73$.

NiskanEN, W. (1971): Representative Government and Bureaucracy (Chicago: Aldine/ Atherton). 
OECD (2007): Performance Management in the OECD Countries (Paris: Organization for Economic Cooperation and Development).

O’Toole, L. J. (2007): Governing Outputs and Outcomes of Governance Networks, in E. Sorenson and J. Torfing, eds., Theories of Democratic Network Governance (Basingstoke: Palgrave).

Olsen, J. P. (forthcoming): The Ups and Downs of Bureaucratic Organization, Annual Review of Political Science 11.

Osborne e Gaebler (1991): Reinventing Government (Reading, MA: Addison-Wesley). Peters, B. G. (2001): The Future of Governing, 2nd Ed. (Lawrence: University Press of Kansas).

. (2004): Back to the Centre? Rebuilding the State, The Political Quarterly, Edição especial em "Restating the State", 130-40.

. (2004): Governance and Public Bureaucracy: New Forms of Democracy or New Forms of Control? Asia-Pacific Journal of Public Administration 26, 3-16. . (2007a): Performance Management in the Nordic Countries, Artigo preparado para a Conferência Annual RAKO, Lidingö, Suécia, Setembro 11.

. (2007b): Central Agencies and Executive Governance, Artigo apresentado no conjunto de oficinas do Consórcio Europeu para Pesquisas Políticas, Maio 7-12. Peters, B. G. e J. Pierre (2004): Politicization of the Public Service: The Quest for Control (Londres: Routledge)

Pierre, J. (2000): Governance, Politics and the State (Basingstoke: Palgrave).

Pollack, J. K. (1951): The Primacy of Politics, American Political Science Review 45, 1-17.

PollitT, C. (2003): Joined Up Government: A Survey, Political Studies Review, 1, 34-49.

Pollitt, C. e C. Talbot (2004): Unbundled Government: A Critical Analysis of the Global Trends to Agencies, Quangos and Contractualisation (Londres: Routledge).

Rokkan, S. (1967): Norway: Corporate Pluralism, in R. A. Dahl, ed., Political Oppositions in Western Democracies (New Haven: Yale University Press).

Rose, R. (1974): The Problem of Party Government (Londres: Macmillan).

Salamon, L. M. (2001): Introduction, in Salamon, ed. The Handbook of Policy Instruments (Nova Iorque: Oxford University Press).

SavoIE, D. J. (2004): Governing from the Centre (Toronto: University of Toronto Press). Scharpf, F. W. (1988): The Joint-Decision Trap: Lessons from German Federalism and European Integration, Public Administration 66, 239-78.

Schofield, J. (2001): The Old Ways are the Best? The Durability and Usefulness of Bureaucracy in Public Sector Management, Organization 8, 77-96.

Sørenson, E. e J. Torfing (2006): Theories of Democratic Network Governance (Londres: Palgrave).

Verhoest, K., P. Humphreys e K. Rubecksen (2007): The Autonomy of Public Agencies: A Comparative Analysis. Manuscrito não publicado, Katholieke Universiteit Leuven, Bélgica.

Von Mettenheim, K. (1997): Presidential Institutions and Democratic Politics: Comparing Regional and National Contexts (Baltimore, MD: Johns Hopkins University Press). 
Walsh, H. e J. Stewart (1992): Change in the Management of the Public Service, Public Administration 70, 499-518.

Wanna, J., L. Jensen e J. De Vries (2003): Controlling Public Expenditure: The Changing Role of Central Budget Agencies - Better Guardians? (Cheltenham: Edward Elgar).

Whitford, A. B. (2002): Decentralization and Political Control in Bureaucracy, Journal of Theoretical Politics 14, 167-93.

Yesilkagit. K. (2007): Whose Regulators? Competing Perspectives on Bureaucratic Autonomy, Artigo apresentado na Reunião Bi-anual do Consórcio Europeu para Pesquisa Política, Pisa, Itália, Setembro 6-8. 


\section{Resumo - Resumen - Abstract}

\section{Os dois futuros do ato de governar: processos de descentralização e recentralização no ato de governar \\ B. Guy Peters}

As reformas do setor público ajudaram a torná-lo mais eficiente e eficaz, mas também geraram vários problemas. Tanto as reformas ao estilo do New Public Management quanto da governança contribuíram para os problemas contemporâneos no ato de governar. Tais problemas têm sido em grande parte políticos, refletindo a tendência de se enfatizar valores administrativos em detrimento dos valores democráticos. Os governos começaram a reagir aos problemas reais e percebidos no setor público desenvolvendo diversos instrumentos de "meta-governança" que podem ajudar a governar organizações públicas, mas que envolvem menos comando e controle diretos. Este artigo aborda as funções de governança contemporâneas na restauração da direção e coerência nas políticas e, ao mesmo tempo, no apoio à autonomia das organizações políticas e no envolvimento de redes de políticas no ato de governar.

Palavras-chave: Governança, New Public Management, direção, administração pública, metagovernança

\section{Los dos futuros del acto de gobernar: procesos de descentralización y recentralización} en el acto de gobernar

\section{B. Guy Peters}

Las reformas del sector público ayudaron en la creación de un sector público más eficiente y eficaz, pero también la creación de diversos problemas. Tanto la reforma de la Nueva Administración Pública como la de la gobernanza concurren a los problemas contemporáneos del acto de gobernar. En gran parte, tales problemas han sido políticos y reflejan la tendencia a enfatizarse los valores administrativos en contra de los democráticos. Los gobiernos empezaron a reaccionar contra los problemas reales del sector público, desarrollando diversos instrumentos de "metagobernanza" que pueden ayudar en el gobierno de las organizaciones públicas, pero que demandan menos mecanismos de controles directos y comando. Este artículo trata de las funciones de gobernanza contemporáneas, de restauración de la dirección y coherencia en las políticas y la implicación de redes de políticas en el acto de gobernar.

Palabras clave: Gobernanza, New Public Management, Dirección, Administración Pública, Metagobernanza.

The Two Futures of Governing: Decentering and recentering processes in governing B. Guy Peters

Reforms of the public sector have helped create a more efficient and effective public sector, but also have created a number of problems. Both the New Public Management and "governance" reforms have contributed to the contemporary problems in governing. These problems have been political to a great extent, reflecting the tendency to emphasize administrative rather than democratic values. Governments have begun to react to the real and perceived problems within the public sector by developing a number of "meat-governance" instruments that can help steer public organizations but which involve less direct command and control. This paper addresses the contemporary governance tasks of restoring political direction and policy coherence while at the 
same supporting the autonomy of public organizations, and the involvement of policy networks, in governing.

Key words: Governance, New Public Management, Steering, Public Administration, Metagovernance

B. Guy Peters

Professor do Departamento de Ciência Política da Universidade de Pittsburgh (EUA).

Contato: bgpeters@pitt.edu 